Abstract THU0397 -Table 1.

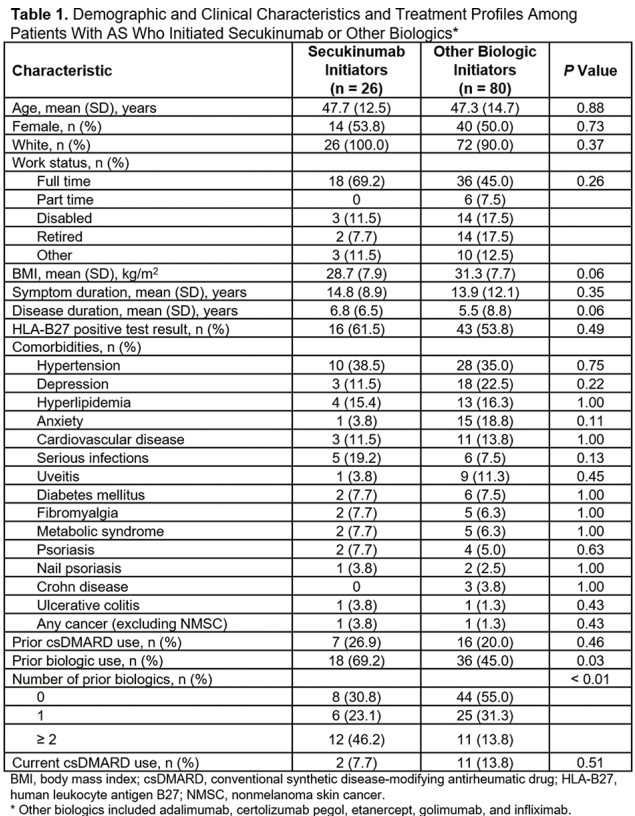

Abstract THU0397 -Table 2.

Table 2. Disease Activity, Quality of Life, and Work Productivity Among Patients With AS Who Initiated Secukinumab or Other Biologics*

\begin{tabular}{|c|c|c|c|}
\hline Characteristic & $\begin{array}{l}\text { Secukinumab } \\
\text { Initiators } \\
(n=26)\end{array}$ & $\begin{array}{l}\text { Other Biologic } \\
\text { Initiators } \\
(n=80)\end{array}$ & $P$ Value \\
\hline ASDAS, mean (SD) [n] & $3.1(0.9)[23]$ & $3.2(0.9)[67]$ & 0.84 \\
\hline $\operatorname{BASDAl}(0-10)$, mean (SD) [n] & $5.7(1.7)[26]$ & $5.4(2.1)[80]$ & 0.52 \\
\hline $\operatorname{BASFI}(0-10)$, mean (SD) [n] & $4.7(2.5)[26]$ & $4.2(2.4)[75]$ & 0.30 \\
\hline $\begin{array}{l}\text { Lateral lumbar flexion (average of left and } \\
\text { right), mean (SD) [n], } \mathrm{cm}\end{array}$ & 30.2 (20.1) [23] & $28.4(21.3)[70]$ & 0.69 \\
\hline Enthesitis, $\mathrm{n} / \mathrm{m}(\%)$ & $12 / 26(46.2)$ & $31 / 80(38.8)$ & 0.50 \\
\hline $\begin{array}{l}\text { SPARCC Enthesitis Index (1-16), } \\
\text { mean (SD) [n] }\end{array}$ & $5.6(3.1)[12]$ & $4.6(2.9)[31]$ & 0.24 \\
\hline Dactylitis, $n / m(\%)$ & $2 / 26(7.7)$ & $2 / 80(2.5)$ & 0.25 \\
\hline Dactylitis count (1-20), mean (SD) [n] & $1.5(0.7)[2]$ & $1.5(0.7)[2]$ & 1.00 \\
\hline Tender joint count (0-68), mean (SD) [n] & $3.3(5.0)[26]$ & $3.7(7.0)[80]$ & 0.39 \\
\hline Swollen joint count $(0-66)$, mean (SD) [n] & $0.4(1.0)[26]$ & $0.9(2.0)[80]$ & 0.61 \\
\hline $\begin{array}{l}\text { Physician global assessment (VAS 0-100), } \\
\text { mean (SD) [n] }\end{array}$ & $40.7(20.3)[26]$ & $41.2(20.9)[80]$ & 0.92 \\
\hline $\begin{array}{l}\text { Physician global assessment of psoriasis } \\
\text { (VAS } 0-100) \text {, mean (SD) }[\mathrm{n}]\end{array}$ & $36.2(19.3)[6]$ & $29.1(22.6)[18]$ & 0.61 \\
\hline Patient pain (VAS 0-100), mean (SD) [n] & $66.6(22.5)[26]$ & $58.9(25.5)[79]$ & 0.21 \\
\hline Patient fatigue (VAS 0-100), mean (SD) [n] & $54.3(26.3)[26]$ & $53.1(25.9)[80]$ & 0.81 \\
\hline Morning stiffness, $\mathrm{n} / \mathrm{m}(\%)$ & & & 0.77 \\
\hline$<30$ minutes & $5 / 26(19.2)$ & $13 / 80(16.3)$ & \\
\hline$\geq 30$ minutes & $21 / 26(80.8)$ & $67 / 80(83.8)$ & \\
\hline HAQ-S (0-3), mean (SD) [n] & $0.78(0.63)[4]$ & $0.99(0.73)[18]$ & 0.61 \\
\hline EQ VAS $(0-100)$, mean (SD) [n] & $55.8(21.3)[26]$ & $55.2(21.6)[80]$ & 0.82 \\
\hline \multicolumn{4}{|l|}{ WPAI domains, mean (SD) [n] } \\
\hline Current employment, $\mathrm{n} / \mathrm{m}(\%)$ & $19 / 26(73.1)$ & $42 / 80(52.5)$ & 0.07 \\
\hline \% Work time missed & $10.7(14.3)[17]$ & $11.9(25.3)[42]$ & 0.32 \\
\hline$\%$ Impairment while working & $43.3(24.4)[19]$ & $36.1(23.8)[42]$ & 0.28 \\
\hline$\%$ Overall work impairment & $46.9(26.4)[17]$ & $41.7(28.8)[42]$ & 0.52 \\
\hline$\%$ Activity impairment & $51.0(28.7)[26]$ & $48.5(28.1)[79]$ & 0.69 \\
\hline \multicolumn{4}{|c|}{$\begin{array}{l}\text { ASDAS, Ankylosing Spondylitis Disease Activity Score; BASDAl, Bath Ankylosing Spondylitis Disease } \\
\text { Activity Index; BAFI, Bath Ankylosing Spondylitit Functional Index; EQ, Euroogl questionnaire; HAQ-S, } \\
\text { Health Assessment Questionnaire for the Spondyloarthropathies; SPARCC, Spondyloarthritis Research } \\
\text { Consortium of Canada; VAS, visual analog scale; WPAI, Work Productivity and Activity Impairment } \\
\text { Questionnaire. } \\
\text { *Other biologics included adalimumab, certolizumab pegol, etanercept, golimumab, and infliximab. }\end{array}$} \\
\hline
\end{tabular}

Conclusion: In this real-world study of US patients with AS, secukinumab initiators had similar demographics, clinical outcomes, disease burden and patient reported outcomes compared with other biologic initiators, with the exception of higher prior biologic use.

Acknowledgement: This study was sponsored by Corrona, LLC. Corrona is supported through contracted subscriptions with multiple pharmaceutical companies. The abstract was a collaborative effort between Corrona and Novartis, with financial support provided by Novartis.

Disclosure of Interests: Alexis Ogdie Grant/research support from: (To my university) Novartis, Pfizer, Grant/research support from: Novartis, Pfizer, Grant/research support from: Novartis, Pfizer, Grant/research support from: Novartis, Pfizer, Consultant for: AbbVie, Bristol-Myers Squibb, Celgene, Corrona, Eli Lilly and Company, Novartis, Pfizer, and Takeda, Consultant for: AbbVie, Amgen, Bristol-Myers Squibb, Celgene, Corrona, Eli Lilly, Novartis, Pfizer Inc, Takeda, Consultant for: Abbvie, Amgen, BMS, Celgene, Corrona, Lilly, Novartis, Pfizer, Takeda, Consultant for: Abbvie, Amgen, BMS, Celgene, Corrona, Lilly, Novartis, Pfizer, Takeda, Mei Liu
Employee of: M. Liu is an employee of Corrona, LLC., Sabrina Rebello Employee of: Corrona, LLC, Meghan Glynn Employee of: M. Glynn is an employee of Corrona, LLC., Robert McLean: None declared, Esther Yi Consultant for: $\mathrm{E}$. $\mathrm{Yi}$ is a postdoctoral fellow at the University of Texas at Austin and Baylor Scott and White Health, providing services to Novartis Pharmaceuticals Corporation., Yujin Park Employee of: Y. Park is an employee of Novartis., Philip J. Mease Grant/research support from: AbbVie, Amgen, BMS, Celgene, Janssen, Lilly, Novartis, Pfizer, SUN and UCB, Consultant for: AbbVie, Amgen, BMS, Galapagos, Gilead Sciences, Inc., Janssen, Lilly, Novartis, Pfizer, SUN and UCB, Speakers bureau: AbbVie, Amgen, BMS, Celgene, Genentech, Janssen, Lilly, Novartis, Pfizer and UCB

DOI: 10.1136/annrheumdis-2019-eular.1642

\section{THU0398 GAIT 3D KINEMATICS UNVEILS A SPECIFIC PATTERN IN PATIENTSIN EARLY YEARS OF AXIAL SPONDYLOARTHRITIS INDEPENDENT OF THEIR BODY COMPOSITION AND MUSCLE PERFORMANCE VARIABLES}

Fernando Pimentel dos Santos ${ }^{1}$, Lucia Domingues ${ }^{2}$, César Mendes ${ }^{2}$, Ricardo Matias ${ }^{3}$, Santiago Rodrigues-Manica ${ }^{2}$, Carolina Crespo ${ }^{2}$, Jaime Branco ${ }^{2}$ ${ }^{1}$ NOVA University of Lisbon, CEDOC, NOVA Medical School/faculdade ciências médicas, Lisboa, Portugal; ${ }^{2}$ NOVA University of Lisbon, CEDOC, NOVA Medical School/faculdade ciências médicas, Lisbon, Portugal; ${ }^{3}$ Champalimaud Research, Champalimaud Centre for the Unknown, Lisbon, Portugal

Background: Axial spondyloarthritis (axSpA) is a chronic inflammatory rheumatic disease characterized by a progressive mobility reduction of the rachis. The postural changes may cause balance problems with gait repercussions. However we lack information during the early years of the disease regarding gait pattern and the possible variables that may influence gait parameters.

Objectives: In order to gain insight into the gait patterns in patients at early stages of axSpA and the potential influence of some patient-specific features, the aim of this study was therefore to evaluate: (i) the 3D gait signature in patients at early years of $\operatorname{axSpA}$; and (ii) the relation between gait parameters, and body composition and muscle performance variables.

Methods: A cross-sectional study was conducted on 46 participants (1850 years old), 23 patients with axSpA (according to ASAS criteria, with less than 10 years since symptoms onset) and 23 healthy controls, matched by gender and age, with a mean age of $37 \pm 7.5$ years, predominantly males $(60 \%)$. The patients with axSpA had $5 \pm 3.2$ years of disease duration, with BASDAI and BASFI of $3 \pm 2.2$ and $2 \pm 2.9$, respectively. Subjects' movement was reconstructed using a 3D full-body kinematic model (Kinetikos, Coimbra, Portugal) fed by 15 inertial sensors placed in the head, arms, trunk, pelvis, thighs, shanks and feet. The primary outcomes comprise the general gait parameters such as gait deviation index, speed, cadence, stance duration, body vertical regularity (sample entropy), step length, range of movement and peak velocity of the different joints. Body composition was assessed by performing octapolar multifrequency bioelectrical impedance analysis (BIA; InBody 770). Muscle performance was assessed with a 60 second sit-to-stand test (STS60), while physical activity was controlled by the international physical activity questionnaire (IPAQ).

Variables (except age, disease duration, BASDAI, BASFI) are presented as median. Non-parametric tests were used to compare groups. Correlations between gait, body composition and skeletal muscle function parameters, were performed.

Results: Gait analysis showed statistically significant differences between axSpA and healthy control groups on gait deviation index (median 83 vs $87 \%, p=0.022$, with higher score values representing similar performance to normal movement), speed (median 0.79 vs $0.85 \mathrm{~m} / \mathrm{s}, \mathrm{p}=0.015$ ), stance duration at the left side (median 68 vs $67 \mathrm{~s}, \mathrm{p}=0.027$ ), left step length (median 0.47 vs $0.49 \mathrm{~m}, \mathrm{p}=0.008$ ), and vertical regularity (median 0.39 vs $0.33, p=0.029$, with higher values representing a less regular and predictable movement pattern). At the sagittal plane, patients showed higher values of left arm maximum flexion (median 14 vs $10^{\circ}, \mathrm{p}=0.011$ ), lower lumbar extension peak velocity (median 45 vs $60 \% \mathrm{~s}, \mathrm{p}=0.016$ ) and higher ankle angular peak velocity on right side (median 330 vs $299 \%$ s, $\mathrm{p}=0.020$ ). However, no statistically significant differences between groups were found for physical activity. In addition, no statistically significant correlation was found between the gait parameters and weight, body fat, torso fat, visceral fat, body mass index, total body water, extracellular water, fat free mass, lean mass, bone mineral content and STS60.

Conclusion: These results provide evidence that although young axSpA patients at early years of the disease display a particular gait pattern 
and this behavior does not seem to be influenced by the body composition and muscle performance. The main determinant for this gait pattern remains an open question.

Disclosure of Interests: Fernando Pimentel dos Santos Grant/research support from: From Abbvie and Novartis, Speakers bureau: Abbvie, Novartis, Pfizer, Biogen, Lucia Domingues: None declared, César Mendes: None declared, Ricardo Matias: None declared, Santiago RodriguesManica: None declared, Carolina Crespo: None declared, Jaime Branco: None declared

DOI: 10.1136/annrheumdis-2019-eular.7491

\section{THU0399 DEVELOPMENT OF AN OPTIMIZED ONLINE SELF- REFERRAL TOOL FOR EARLY RECOGNITION OF PATIENTS WITH AXIAL SPONDYLOARTHRITIS (AXSPA) - DATA FROM THE 'OPTIREF'-STUDY}

Fabian Proft ${ }^{1}$, Laura Spiller ${ }^{1}$, Mikhail Protopopov ${ }^{1}$, Valeria Rios Rodriguez ${ }^{1}$, Burkhard Muche ${ }^{1}$, Judith Rademacher ${ }^{1}$, Susanne Lüders ${ }^{1}$, Anne Katrin Weber ${ }^{1}$, Imke Redeker ${ }^{1,2}$, Denis Poddubnyy ${ }^{1,2}$. ${ }^{1}$ Charité Universitätsmedizin, Berlin, Department of Gastroenterology, Infectiology and Rheumatology, 12203 Berlin, Germany; ${ }^{2}$ German Rheumatism Research Centre, Berlin, Germany

Background: One of the major reasons for a long diagnostic delay in axial spondyloarthritis (axSpA) is the late referral of patients by primary care physicians dealing with patients with chronic back pain. We developed and implemented an online self-referral tool (www.bechterew-check de), which gave access to a rheumatological consultation if patients declared suffering from chronic back pain ( $\geq 3$ months) with a symptom onset $\leq 45$ years of age, and at least one feature indicative of SpA. In the prospective "Identification of the Optimal Referral Strategy for Early Diagnosis of Axial Spondyloarthritis (OptiRef) Study" we could diagnose axSpA in $19 \%$ of the self-referred patients [1].

Objectives: To optimize the online-self-referral tool for recognition of patients with high suspicion of axSpA in order to increase the specificity by keeping the high level of sensitivity.

Methods: 181 patients who had fulfilled the online self-referral strategy were included and underwent a standardized rheumatology examination. The final diagnosis of axial $\mathrm{SpA} / \mathrm{no}$ axial $\mathrm{SpA}$ by the rheumatologist served as the gold standard. The performance of all possible combinations of the referral parameters (13 parameters in total including 5 features of inflammatory back pain (IBP) and 8 other SpA features) added to both stem parameters (chronic back pain starting at age of $\leq 45$ years) was tested. In addition, the following pre-specified combinations were evaluated: 1) $\geq 1$ IBP parameter AND $\geq 1$ other SpA parameter, 2) $\geq 1$ IBP parameter $\mathrm{OR}>1$ other SpA parameter. For all combinations, a sensitivity, a specificity, positive and negative predictive values (PPV and NPV), as well as a positive and negative likelihood ratio (LR+ and LR-) were calculated. We targeted the maximal specificity by acceptable sensitivity (defined as $\geq 90 \%$ of the original strategy).

Results: For 163 of the included patients, full data of the online questionnaire as well as of rheumatology examination including the final diagnosis was available. $31(19 \%)$ of them were diagnosed with axial SpA. Raising the threshold of the number of positive parameters (table 1) resulted in a quick drop of the sensitivity. According to the pre-defined selection criterion, only a strategy with any four positive parameters would be acceptable. An analysis of combined strategies (IBP parameters and/ or other SpA parameters) resulted into identification of a strategy with an improved performance: a combination of $\geq 2$ IBP parameters with $\geq 1$ other SpA parameters (in addition to both stem parameters) showed a sensitivity of $90 \%(28 / 31)$, a specificity of $27 \%$ (35/132), a PPV of $22 \%$ $(28 / 125)$, a NPV of $92 \%$ (35/38), LR+ of 1.23 and LR- of 0.36 . Thus, identifying 28 of 31 patients with axSpA would have been possible after the assessment of 125 patients instead of 163 .

Conclusion: The data-driven optimized online self-referral tool (figure 1) requires the following parameters to be positive: chronic back pain ( $\geq 3$ months) plus back pain onset before 45 years of age plus $\geq 2$ IBP parameters plus $\geq 1$ other $\mathrm{SpA}$ feature. The performance of this tool should be confirmed in a prospective study.
Abstract THU0399 -Table 1.

Table 1: Performance of self-referral strategies based on combinations of SpA parameters in addition to the stem parameters (chronic back pain starting at age of $\leq 45$ years).

\begin{tabular}{|c|c|c|c|c|c|c|c|}
\hline $\begin{array}{l}\text { Number of } \\
\text { furfiled } \\
\text { cinterio* }^{*}(2)\end{array}$ & $\begin{array}{l}\text { Number of } \\
\text { patients }\end{array}$ & $p p v$ & NoV & Sensitivity & Specificity & LRt & LR. \\
\hline 10esta & 163 & $0.19(31 / 163)$ & & $1.00(31 / 31)$ & & & \\
\hline 2 & 158 & $0.20(31 / 158)$ & $1.00(5 / 5)$ & $1.00(31 / 31)$ & $0.04(5 / 132)$ & 1.04 & 0.00 \\
\hline 3 & 147 & $0.21(31 / 147)$ & $1.00(16 / 115)$ & $1.00(31 / 31)$ & $0.12(16 / 132)$ & 1.14 & 0.00 \\
\hline 4 & 128 & $0.22(28 / 128)$ & $0.91(32 / 35)$ & $0.50(28 / 31)$ & $0.24(32 / 132)$ & 1.19 & 0.40 \\
\hline 5 & 114 & $0.23(26 / 114)$ & $0.50(44 / 49)$ & $0.84(26 / 31)$ & $0.33(44 / 132)$ & 1.26 & 0.48 \\
\hline 6 & 74 & $0.31(23 / 74)$ & $0.91(81 / 89)$ & $0.74(23 / 31)$ & $0.61(81 / 132)$ & 1.92 & 0.42 \\
\hline 7 & 48 & $0.38(18 / 48)$ & $0.89(102 / 115)$ & $0.58(18 / 31)$ & $0.77(102 / 132)$ & 2.55 & 0.54 \\
\hline 8 & 27 & $0.48(13 / 27)$ & $0.87(118 / 136)$ & $0.42(13 / 31)$ & $0.89(118 / 132)$ & 3.95 & 0.65 \\
\hline 9 & 17 & $0.59(10 / 17)$ & $0.86(125 / 145)$ & $0.32(10 / 31)$ & $0.95(125 / 132)$ & 6.08 & 0.72 \\
\hline 10 & 7 & $0.43(3 / 7)$ & $0.82(128 / 156)$ & $0.10(3 / 31)$ & $0.97(128 / 132)$ & 3.19 & 0.93 \\
\hline 11 & 1 & $1.00(1 / 1)$ & $0.81(132 / 162)$ & $0.03(1 / 31)$ & $1.00(132 / 132)$ & $\cdot$ & 0.97 \\
\hline 12 & 1 & $1.00(2 / 1)$ & $0.81(132 / 162)$ & $0.03(1 / 31)$ & $1.00(132 / 132)$ & $\cdot$ & 0.97 \\
\hline 13 & 1 & $1.00(1 / 1)$ & $0.81(132 / 162)$ & $0.03(1 / 31)$ & $1.00(132 / 132)$ & & 0.97 \\
\hline
\end{tabular}

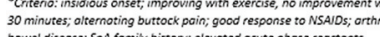

-The original strotegy, reference for the colculation of the performonce of oll other strotegies

Acknowledgements: The OptiRef project was supported by an unrestricted research grant from Novartis.

\section{REFERENCES:}

1. Proft F, et al. EULAR 2018, Abstract THU0230.

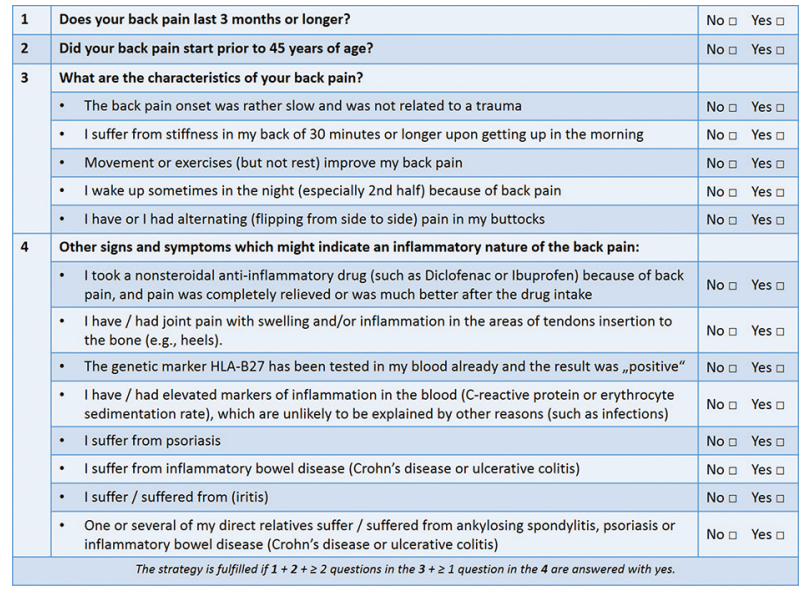

Abstract THU0399 - Figure 1. The data-driven optimized self-referral strategy.

Disclosure of Interests: Fabian Proft Grant/research support from: Novartis, Consultant for: yes but less than 10.000, Paid instructor for: yes but less than 10.000, Speakers bureau: yes but less than 10.000, Laura Spiller: None declared, Mikhail Protopopov: None declared, Valeria Rios Rodriguez: None declared, Burkhard Muche Speakers bureau: Yes less than 10.000, Judith Rademacher: None declared, Susanne Lüders: None declared, Anne Katrin Weber: None declared, Imke Redeker: None declared, Denis Poddubnyy Grant/research support from: AbbVie, Merck Sharp \& Dohme, Novartis, Consultant for: AbbVie, Bristol-Myers Squibb, Janssen, Merck Sharp \& Dohme, Novartis, Pfizer, UCB Pharma, Speak ers bureau: AbbVie, Bristol-Myers Squibb, Janssen, Merck Sharp \& Dohme, Novartis, Pfizer, Roche, UCB Pharma DOI: 10.1136/annrheumdis-2019-eular.4688

\section{THU0400 COMPLICATIONS OF ANTERIOR UVEITIS ASSOCIATED WITH HLA-B27 ANTIGEN IN PATIENTS WITH AND WITHOUT SPONDYLOARTHRITIS}

Irina Razumova ${ }^{1}$, Alla Godzenko ${ }^{2}$, Irina Guseva ${ }^{2} .{ }^{1}$ Research Institute of Eye Disease, Moscow, Russian Federation; ${ }^{2}$ Nasonova Research Institute of Rheumatology, Moscow, Russian Federation

Background: HLA-B27- associated anterior uveitis (AU) can be an isolated disease or part of a systemic inflammatory process, such as spondyloarthritis. Differences in the outcome of uveitis with and without spondyloarthritisare still under researh. 